\title{
Recanalisation of an occluded modified Blalock-Taussig shunt by balloon dilatation
}

Narayanswami Sreeram, Kevin Walsh, Ian Peart

\begin{abstract}
A four year old boy with pulmonary atresia and ventricular septal defect had an acute cyanotic episode three years after undergoing a right-sided, $6 \mathrm{~mm}$ diameter, modified Blalock-Taussig shunt. On admission no continuous murmur could be heard from the shunt and the typical high velocity, continuous flow profile of the shunt could not be identified by Doppler echocardiography. At catheterisation a right subclavian artery angiogram confirmed shunt occlusion. From the subclavian artery, an 0.035 inch wire was used to enter the occluded shunt and then the pulmonary artery. Balloon angioplasty of the entire length of the shunt was performed with $6 \mathrm{~mm}$ diameter balloon. After angioplasty the arterial oxygen saturation increased from $63 \%$ to $83 \%$. The patient was treated with intravenous heparin followed by warfarin. Repeat catheterisation and angiography eight days later confirmed wide patency of the shunt.
\end{abstract}

(Br Heart f 1993;70:474-475)

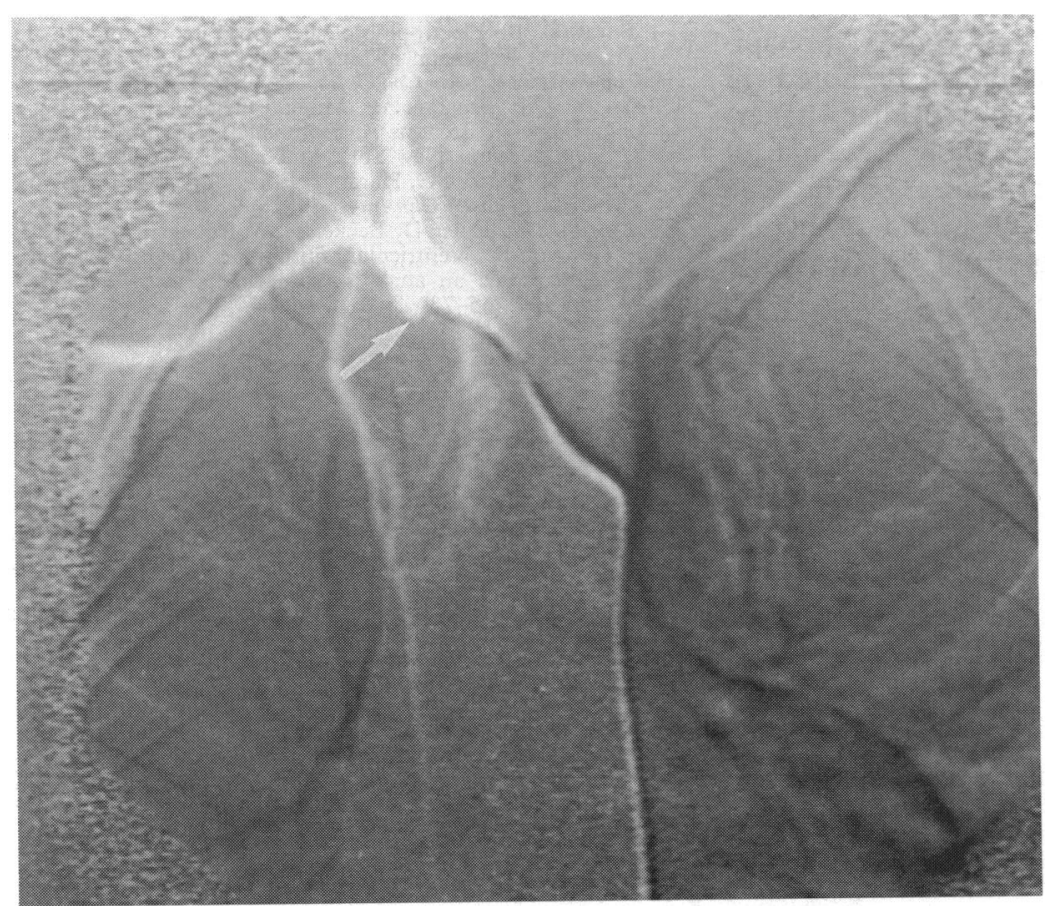

Figure 1 Right subclavian artery angiogram showing occlusion of the right sided modified Blalock-Taussig shunt (arrow).
Modified Blalock-Taussig shunts with interposition tube grafts between the subclavian artery and pulmonary artery are standard palliative treatment for various cyanotic congenital heart defects. ${ }^{1} \mathrm{~A}$ major complication is shunt occlusion, which often requires emergency surgical revision. ${ }^{2}$ Transcatheter balloon dilatation of both occluded peripheral arteries and of stenosed (but not occluded) Blalock-Taussig shunts have been described previously. We describe successful recanalisation of an occluded modified Blalock-Taussig shunt in a child.

\section{Case report}

A four year old boy presented shortly after birth with moderate central cyanosis. A diagnosis of pulmonary atresia with ventricular septal defect, confluent central pulmonary arteries, and multiple aortopulmonary collateral vessels was based on echocardiography and cardiac catheterisation. At the age of 12 months he underwent a right-sided modified Blalock-Taussig shunt $(6 \mathrm{~mm}$ Gore-tex graft), after which he was treated with oral aspirin and dipyridamole at standard doses. He presented to his local hospital three years later with acute onset of cyanosis, associated with absence of a continuous murmur from the shunt. He was referred to our hospital.

At admission he had severe cyanosis with a systemic arterial oxygen saturation of $63 \%$. Doppler echocardiography did not show the continuous high velocity flow profile associated with the shunt. His parents gave informed consent and cardiac catheterisation was performed the next day. A retrograde femoral arterial approach was used to obtain a right subclavian artery angiogram with a $5 \mathrm{~F}$ Cobra (Cordis) catheter. This confirmed complete occlusion of the shunt (fig 1). An 0.035 inch stiff, angled hydrophilic wire (180 $\mathrm{cm}$, Terumo) was introduced into the shunt and advanced to the left pulmonary artery (fig 2A), followed by the catheter. The wire was exchanged for an 0.018 inch $(175 \mathrm{~cm})$ UltraSelect nitinol guidewire (Microvena) with a $4 \mathrm{~cm}$ angled flexible tip. A $6 \mathrm{~mm}$ diameter Tyshak balloon (NuMed) was advanced into the shunt over the wire and multiple inflations were performed along the length of the shunt. The arterial oxygen saturation increased to $83 \%$. Angiography showed a widely patent shunt (fig $2 \mathrm{~B}$ ). Initially intravenous heparin was given as anticoagulant therapy and subsequently oral warfarin was given. The patient was discharged from 

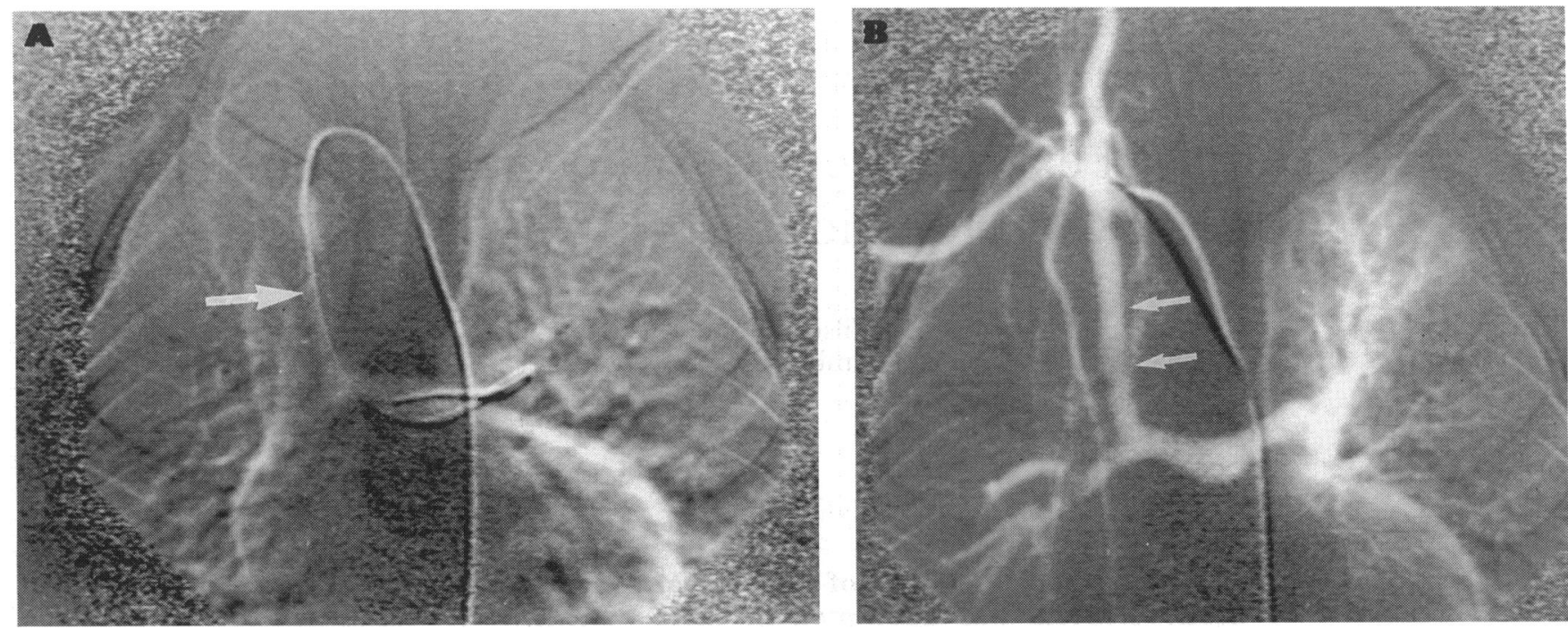

Figure 2 (A) Radiograph after introduction of a wire through the occluded Blalock-Taussig shunt (arrow) and into the left pulmonary artery.

(B) Angiogram after balloon dilatation of the shunt showing a widely patent shunt (arrows) filling both branch pulmonary arteries.

hospital 12 days later. Before discharge, repeat cardiac catheterisation and angiography confirmed that the shunt was patent.

\section{Discussion}

The modified Blalock-Taussig shunt is the standard palliative surgical treatment for various cyanotic heart lesions. ${ }^{1}$ For complex lesions, further corrective surgical interventions may not be feasible, and prolonged patency of the shunt is essential for long-term palliation. However, interposition shunts between the subclavian and pulmonary artery are liable to become stenosed or occluded. ${ }^{2}$ Transcatheter balloon dilatation of stenosed shunts has been proposed as an alternative to surgical revision. Most have been performed for stenosed classical Blalock-Taussig shunts, where direct end-to-side anastomosis of the subclavian artery to the pulmonary artery has been performed. ${ }^{3-5}$ There is, however, a wealth of experience with balloon dilatation and recanalisation of occluded peripheral arteries in adult patients. ${ }^{6-8} \mathrm{~A}$ major limitation in the application of this technique for occluded systemic to pulmonary artery shunts in children is that patients in whom the shunt was the major (or singular) source of pulmonary blood flow often have severe hypoxia and metabolic acidosis at presentation and therefore require emergency surgical intervention. Prolonged attempts at transcatheter recanalisation of the shunt are not without risk in such situations. When other sources of pulmonary blood flow in the form of aortopulmonary collateral arteries or a patent but stenosed pulmonary valve are present, however, the patient is often in a stable haemodynamic state despite shunt occlusion. In such patients transcatheter balloon dilatation and recanalisation of a recently occluded shunt may have an important role.

1 de Laval MR, McKay R, Jones M, Stark J, Macartney FJ. Modified Blalock-Taussig shunt. $\mathcal{f}$ Thorac Cardiovasc Surg 1981;81:112-9.

2 Kay PH, Capuani A, Franks R, Lincoln C. Experience with the modified Blalock-Taussig operation using polytetrafluoroethylene (Impra) grafts. Br Heart $\mathcal{f} 1983$; 49:359-63.

3 Fischer DR, Park SC, Neches WH, Beerman LB, Fricke FJ, Mathews RA, et al. Successful dilatation of a stenotic Blalock-Taussig anastomosis by percutaneous transluminal balloon angioplasty. Am $\mathcal{F}$ Cardiol $1985 ; 55$ 861-2.

4 Marx GR, Allen HD, Ovitt TW, Hanson W. Balloon dilation angioplasty of Blalock-Taussig shunts. $\mathrm{Am} \mathcal{F}$ Cardiol 1988;62:824-7.

5 Qureshi SA, Martin RP, Dickinson DF, Hunter S. Balloon dilatation of stenosed Blalock-Taussig shunts. Br Heart $\mathcal{f} 1989 ; 61: 432-4$.

6 Dotter CT, Judkins MP. Transluminal treatment of arteriosclerotic obstruction: description of a new technique and a preliminary report of its application. Circulation 1964;30:654-70.

7 Gruentzig A, Hopff H. Perkutan rekanalisation chronischer arterieler verschlusse mit einem neven dilationskatheter modifikation der Dottertechnik. Dtsch Med Wochenschr 1974;99:2502-5.

8 Morgenstern BR, Getrajdman GI, Laffey KJ, Bixon R Martin EC. Total occlusions of the femoropoplitea artery: high technical success rate of conventional balloon angioplasty. Radiology 1989;172:937-40. 